\title{
Tension gastrothorax: acute life-threatening manifestation of late onset congenital diaphragmatic hernia $(\mathrm{CDH})$ in children
}

Pål Aksel Næss ${ }^{1,2^{*}}$, Joachim Wiborg ${ }^{1,2}$, Kristin Kjellevold $^{1,2}$ and Christine Gaarder ${ }^{2}$

\begin{abstract}
Tension gastrothorax in children is a life-threatening condition and presents dramatically with acute and severe respiratory distress. It develops when an intra-thoracic stomach herniated through a diaphragmatic defect is massively distended by trapped air and/or fluid causing mediastinal displacement. Tension gastrothorax is often misinterpreted as tension pneumothorax and managed as such leading to increased morbidity and mortality. We present a child with tension gastrothorax and a literature review of this phenomenon. Immediate clinical and radiographic evaluation should lead to accurate diagnosis followed by emergency decompression of the stomach before laparotomy with reduction of herniated viscera and repair of the diaphragmatic defect.
\end{abstract}

Keywords: Tension gastrothorax, Laparotomy, Children

\section{Background}

Tension gastrothorax presents dramatically with acute and severe respiratory distress. It develops when the stomach herniated through a left-sided diaphragmatic defect into the thorax is massively distended by trapped air and/or fluid. The term tension gastrothorax first appeared in the literature in 1984 as a complication of traumatic rupture of the diaphragm in an adult [1]. However, in childhood this phenomenon is dominantly caused by a herniation of the stomach through a posterolateral congenital diaphragmatic defect [2-4]. This article focuses on symptoms, diagnosis and treatment of this life-threatening condition in children based on a case report and review of the literature.

\section{Case presentation}

\section{Case report}

A previously healthy 9-year-old boy presented to the emergency department with a $6 \mathrm{~h}$ history of left chest pain and increasing respiratory distress. His respiratory rate was $40 / \mathrm{min}$ and heart rate was $105 / \mathrm{min}$, cardiac

\footnotetext{
* Correspondence: paanae@ous-hf.no

'Department of Traumatology, Oslo University Hospital Ulleval, Nydalen postbox 4956, N-0424, Oslo, Norway

${ }^{2}$ Department of Gastrointestinal and Pediatric Surgery, Oslo University

Hospital Ulleval, Nydalen, Norway
}

\section{Biomed Central}

auscultation was unremarkable, auscultation of lung fields revealed diminished breath sound over the left side. A chest X-ray (Fig. 1) showing a large air-fluid level in the left hemithorax with shift of the mediastinum to the right was interpreted as tension gastrothorax. Prompt insertion of a nasogastric tube with evacuation of air and $800 \mathrm{ml}$ of gastric content led to immediate relief of symptoms. Subsequent chest $\mathrm{x}$-ray showed normalization of the mediastinal shift and the nasogastric tube was found to curve back into the left hemithorax (Fig. 2). On the same day, the patient underwent repair of a $5 \times 5 \mathrm{~cm}$ posterolateral defect in the left diaphragm after the stomach and spleen were repositioned in the abdominal cavity. The postoperative course was uneventful and he was discharged home 7 days after surgery. He remained well at follow-up 2 and 8 months later and chest $\mathrm{x}$-ray was normal (Fig. 3).

\section{Discussion}

Tension gastrothorax describes mediastinal shift by a distended intrathoracic stomach herniated through a congenital or acquired diaphragmatic defect [1-3]. Most 

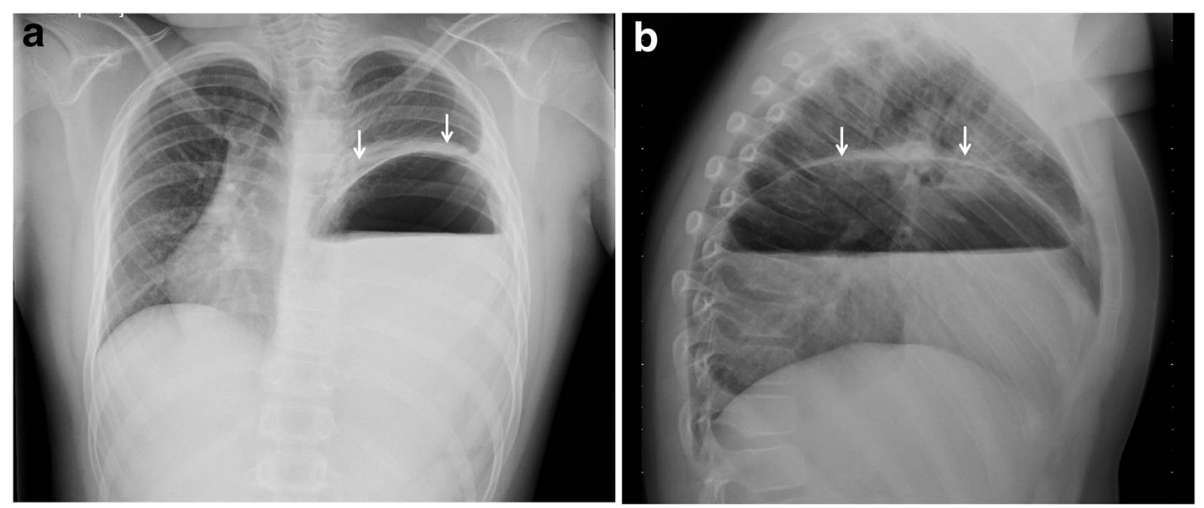

Fig. 1 Anteroposterior (a) and lateral (b) chest radiographs with large air-fluid level in left hemithorax. Note superior rim formed by stomach wall and compressed lung (arrows) and mediastinal shift to the right

pediatric cases are left-sided and the stomach has herniated through a congenital posterolateral (Bochdalek) defect [3].

Congenital diaphragmatic hernia $(\mathrm{CDH})$ occurs in 1 in 2500-4000 live births and the vast majority are diagnosed prenatally or shortly after birth due to respiratory distress $[5,6]$. However, approximately $10 \%$ of patients with $\mathrm{CDH}$ present later in life $[2,7,8]$. Late presentation of $\mathrm{CDH}$ presents diagnostic difficulty due to its rarity and misleading symptoms and signs $[2,3,7,8]$. In childhood the clinical presentation varies from nonspecific symptoms like chest pain and abdominal pain, failure to thrive and recurrent pulmonary infection to severe respiratory distress and eventually circulatory collapse caused by a fully developed tension gastrothorax [2, 3, 7-9].
A likely chain of pathophysiology events leading to tension gastrothorax is described by Horst et al. [2]. At some point increased abdominal pressure herniates the stomach through a preexisting defect in the diaphragm. Then tension gastrothorax may occur at any time when the stomach suddenly fills with air, fluid or food through a one-way valve mechanism created by abnormal angulation of the gastroesophageal junction combined with gastric outlet obstruction caused at the level of the diaphragm $[2,3]$.

The clinical picture of tension gastrothorax with acute respiratory distress and reduced or absent breath sounds in the left hemithorax in an otherwise well child has commonly been mistaken for a tension pneumothorax and managed as such leading to increased morbidity and mortality $[3,8-10]$.

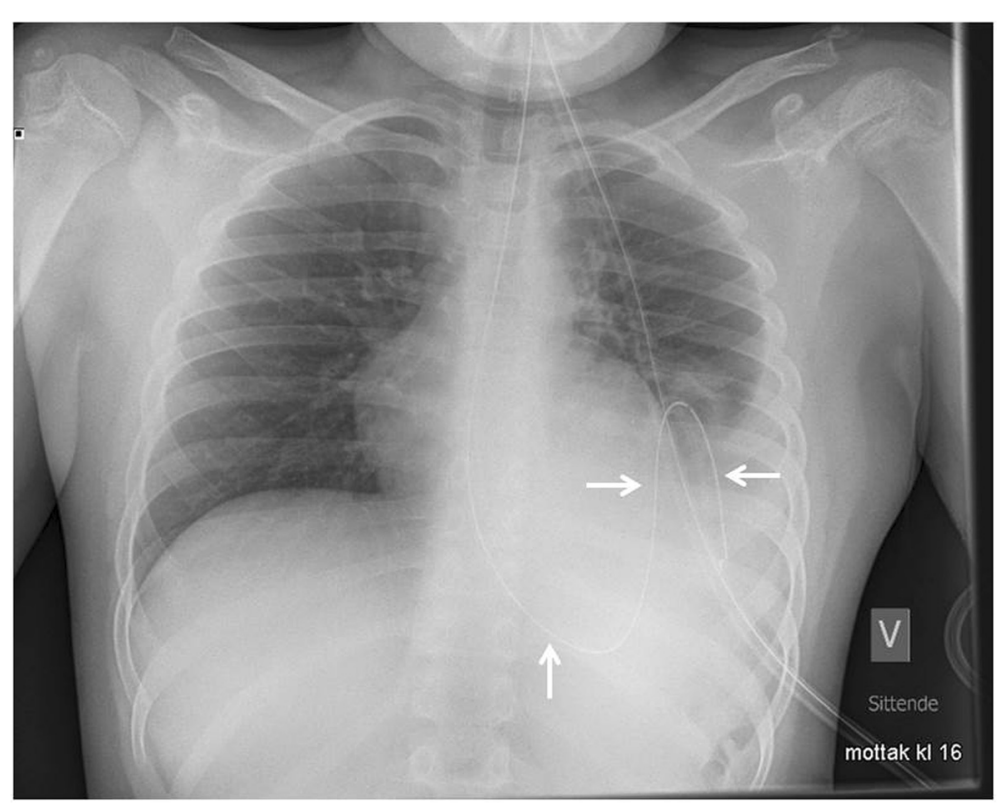

Fig. 2 Chest $x$-ray after gastric decompression. Note the normalization of the mediastinal shift and the gastric tube as it curves back into the left hemithorax (arrows) confirming the intrathoracic position of the stomach 


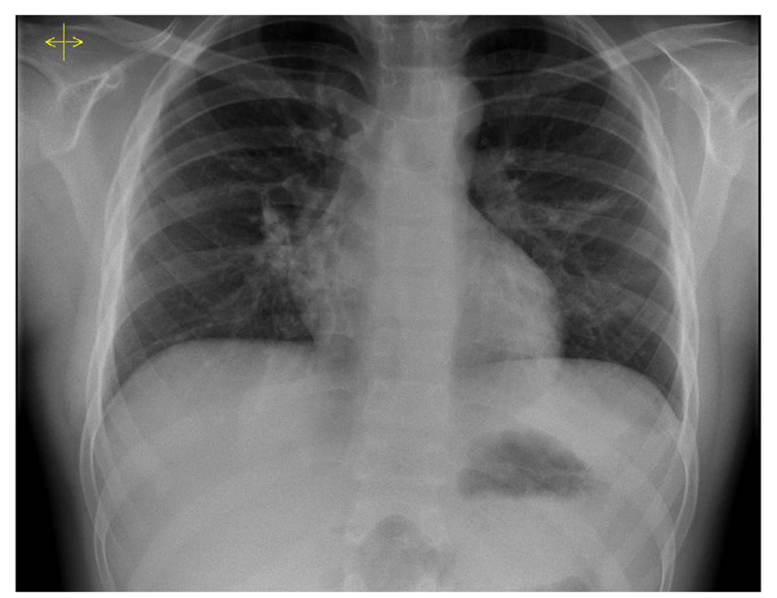

Fig. 3 Chest x-ray at follow-up 2 months after surgical repair of the diaphragmatic defect. Note normal position of the stomach bubble and the normal diaphragmatic contour

The proper interpretation of the chest $\mathrm{x}$-ray becomes crucial when differentiating between the above mentioned diagnoses. The radiological findings of a tension gastrothorax include: a large air-filled structure with or without a fluid level in the left hemithorax, a superior rim formed by compressed ipsilateral lung and stomach wall, lack of a stomach bubble in the left upper quadrant, the left hemidiaphragm will be poorly defined as well as mediastinal shift to the right (Fig. 1) [2, 3, 10, 11].

Although mediastinal shift to the right is evident in a left-sided tension pneumothorax, the following features will allow clear-cut distinction from tension gastrothorax: the entire left lung is centrally compressed and all surrounded by intrapleural air, the lateral sinus is free and the left (depressed) hemidiaphragm well-defined [2, 3, 11]. Moreover, a tension pneumothorax in an otherwise healthy child is an uncommon event [10].

The management of tension gastrothorax is immediate placement of a large-bore naso- or orogastric tube to decompress the dilated stomach $[2,3,8,12]$. Intubation of the intrathoracic segment may be difficult [10]. The position of the tube on a chest $x$-ray as it curves back into the chest is a very helpful and virtually diagnostic finding (Fig. 2) [11]. Instant clinical improvement should occur after stomach decompression [10]. If this maneuver fails, transthoracic needle decompression of the stomach in a lower intercostal space guided by the chest $\mathrm{x}$-ray is recommended $[2,3]$. If deflation of the stomach is not accomplished the mediastinal shift can impair venous return and lead to cardiac arrest $[3,12-14]$.

Definitive management after initial resuscitation in this emergency is operative repair. Laparotomy is the access of choice [3, 4]. It allows quicker reduction and inspection of the abdominal viscera and easy repair of the diaphragmatic defect $[2,14]$. In an otherwise healthy child, as in the presented case, an uneventful recovery can be expected [2].

\section{Conclusions}

Although rare, tension gastrothorax must be included in the differential diagnosis in a previously healthy child with acute onset of severe respiratory distress to allow prompt life-saving action. Immediate clinical and radiographic evaluation leads to accurate diagnosis and should be followed by emergency decompression of the stomach before laparotomy with reduction of herniated viscera and repair of the diaphragmatic defect.

\section{Consent}

Written informed consent was obtained from the legal guardians of the patient for publication of this Case report and the accompanying images. A copy of the written consent is available for review by the Editor-inChief of this journal.

\section{Competing interest}

The authors declare that they have no competing interests.

\section{Authors' contributions}

PAN: Study design, drafted the manuscript, wrote and critically reviewed the manuscript. JW: Study design and critically reviewed the manuscript. KK: Study design and critically reviewed the manuscript. CG: Study design, co-wrote and critically reviewed the manuscript. All authors have read and approved the final manuscript and agree to be accountable for all aspects of the work.

Received: 18 March 2015 Accepted: 8 June 2015

Published online: 24 June 2015

\section{References}

1. Ordog J, Wasserberger J, Balasubramanian S. Tension Gastrothorax complicating post-traumatic rupture of the diaphragm. Am J Emerg Med. 1984;2:219-21.

2. Horst M, Sacher P, Molz G, Willi UV, Meuli M. Tension gastrithorax. J Pediatr Surg. 2005;40:1500-4. 
3. Ng J, Rex D, Sudhakaran N, Okoye B, Mukhtar Z. Tension gastrothorax in children: Introducing a management algorithm. J Pediatr Surg. 2013;48:1613-7.

4. Fuller G, Cacala S, Oosthuizen G. Tension gastrothorax-colothorax secondary to traumatic diaphragmatic hernia. Pediatr Emerg Care. 2010;26:299-301.

5. Wenstrom KD, Wiener CP, Hanson JW. A five year state wide experience with congenital diaphragmatic hernia. Am J Obstet Gynecol. 1991;165:838-42.

6. Langham Jr MR, Kays DW, Ledbetter DJ, et al. Congenital diaphragmatic hernia, Epidemiology and outcome. Clin Perinatol. 1996;23:671-88.

7. Nitecki S, Bar-Maor JA. Late presentation of Bochdalek hernia; our experience and review of the literature. Isr Med Sci. 1992;28:711-4.

8. Coren ME, Rosenthal M, Bush A. Congenital diaphragmatic hernia misdiagnosed as tension pneumothorax. Pediatr Pulmomnol. 1997;24:119-21.

9. Zedan M, El-Ghazaly M, Fouda A, El-Bayoumi M. Tension gastrothorax: a case report and review of the literature. J Pediatr Surg. 2008;43:740-3.

10. Snyder HS, Salo DF, Kelly PH. Congenital Diaphragmatic hernia presenting as massive gastrothorax. Ann Emerg Med. 1990;19:562-4.

11. Muzzafar S, Swischuk LE, Jadhav SP. Radiographic findings in late-presenting congenital diaphragmatic hernia: helpful imaging findings. Pediatr Radiol. 2012:42:337-42.

12. Flamée $P$, Pregardien C. Tension pneumothorax causing cardiac arrest. CMAJ. 2012;184(1), E82.

13. Kutzsche S, Sangolt GK, Schistad O, Sunde S. Severe complications during the management of a child with late presentation of a diaphragmatic hernia. Act Anaesthesiol Scand. 2003;47:1302-4.

14. Rathinam S, Margabanthu G, Jothivel G, Bavanisanker T. Tension gastrothorax causing cardiac arrest in a child. Interact Cardiovasc Thorac Surg. 2002;1(2):99-101.

\section{Submit your next manuscript to BioMed Central and take full advantage of:}

- Convenient online submission

- Thorough peer review

- No space constraints or color figure charges

- Immediate publication on acceptance

- Inclusion in PubMed, CAS, Scopus and Google Scholar

- Research which is freely available for redistribution 